\title{
EDITORIAL
}

\section{La salud pública en Colombia}

\section{Public health in Colombia}

\author{
Doris Olier-Castillo $^{1}$
}

La Salud Pública es una responsabilidad del Estado Colombiano mediante la cual debe garantizar el derecho esencial de protección de la salud individual y colectiva. Por ende el Ministerio de Salud y Protección Social debe responder por nuestras condiciones de bienestar y calidad de vida.

Dentro del tema de Salud Pública hay muchos aspectos a considerar como por ejemplo Gestión de la Salud Pública, Estilos de Vida Saludable, Promoción y Prevención, Salud Ambiental, Vigilancia en Salud Pública, entre otros.

Con respecto a la promoción y prevención el Ministerio menciona que es un "Proceso para proporcionar a las poblaciones los medios necesarios para mejorar la salud y ejercer un mayor control sobre la misma, mediante la intervención de los determinantes de la salud y la reducción de la inequidad. Esto se desarrolla fundamentalmente a través de los siguientes campos: formulación de política pública, creación de ambientes favorables a la salud, fortalecimiento de la acción y participación comunitaria, desarrollo de actitudes personales saludables y la reorientación de los servicios de salud; por sus características la promoción de la salud supone una acción intersectorial sólida que hace posible la movilización social requerida para la transformación de las condiciones de salud"2.

Cuando leo esto no puedo evitar preguntarme, ¿cómo puede el estado "ejercer un mayor control" si la salud está atomizada desde las diferentes IPS que subcontratan las muchas EPS colombianas? ¿Reducción de la inequidad?, pero cada día se escuchan más quejas sobre esto, especialmente de las personas de muy escasos recursos. ¿Promoción de la salud, prevención de la enfermedad? creo que mientras los que manejan las EPS

${ }^{1}$ MSc en Ciencias Básicas Biomédicas, Programa de Bacteriología. Corporación Universitaria Rafael Núñez. Cartagena, Colombia.

2 Tomado de: http://www.minsalud.gov.co/salud/Paginas/Promoci\%C3\%B3nyPrevenci\%C3\%B3n.aspx 
realmente no se preocupen por esto, las IPS nunca lo harán como es debido, porque prevenir enfermedades que después ocasionan grandes costos, se hace con análisis médicos y exámenes paraclínicos que periódicamente se realicen a los afiliados. Eso sí sería establecer una verdadera política de salud pública para prevenir y no estar escuchando que el estado se gastó tanto en enfermedades catastróficas que se hubieran podido evitar. 